\title{
Age Differences in Brain Activity during Emotion Processing: Reflections of Age-Related Decline or Increased Emotion Regulation?
}

\author{
Kaoru Nashiro Michiko Sakaki Mara Mather \\ Davis School of Gerontology, University of Southern California, Los Angeles, Calif., USA
}

\section{Key Words}

Emotion - Aging • Functional magnetic resonance

imaging $\cdot$ Positivity effect $\cdot$ Amygdala $\cdot$ Prefrontal cortex

\begin{abstract}
Despite the fact that physical health and cognitive abilities decline with aging, the ability to regulate emotion remains stable and in some aspects improves across the adult life span. Older adults also show a positivity effect in their attention and memory, with diminished processing of negative stimuli relative to positive stimuli compared with younger adults. The current paper reviews functional magnetic resonance imaging studies investigating age-related differences in emotional processing and discusses how this evidence relates to two opposing theoretical accounts of older adults' positivity effect. The aging-brain model [Cacioppo et al. in: Social Neuroscience: Toward Understanding the Underpinnings of the Social Mind. New York, Oxford University Press, 2011] proposes that older adults' positivity effect is a consequence of age-related decline in the amygdala, whereas the cognitive control hypothesis [Kryla-Lighthall and Mather in: Handbook of Theories of Aging, ed 2. New York, Springer, 2009; Mather and Carstensen: Trends Cogn Sci 2005;9:496502; Mather and Knight: Psychol Aging 2005;20:554-570] argues that the positivity effect is a result of older adults' greater focus on regulating emotion. Based on evidence for structural and functional preservation of the amygdala in older adults and findings that older adults show greater prefrontal
\end{abstract}

cortex activity than younger adults while engaging in emotion-processing tasks, we argue that the cognitive control hypothesis is a more likely explanation for older adults' positivity effect than the aging-brain model.

Copyright $\odot 2011$ S. Karger AG, Basel

In contrast with the age-related declines in many domains of cognitive functioning [1], emotion regulation functioning improves somewhat with age [2]. People experience less negative affect as they get older and can restore their good mood after being induced into a negative mood more effectively than younger adults [3]. Older adults also show a 'positivity effect' in attention and memory [4]. For instance, older adults sometimes spend a larger proportion of time viewing positive items and a smaller proportion viewing negative items than do younger adults [5, 6]. Moreover, in some studies, compared with younger adults, less of what older adults remember is negative and more is positive $[5,7,8]$. Such age by valence interactions tend to have a medium effect size [8]; thus, as might be expected, studies with relatively small participant groups do not always reveal significant age differences. Other factors, such as a level of arousal of stimuli [9], availability of cognitive resources [6] or types of measurements across studies [10], may also account for the presence or absence of a positivity effect.

Why do older adults show some improvements in emotion regulation despite suffering age-related cogni-

\section{KARGER}

Fax +41613061234 E-Mail karger@karger.ch www.karger.com

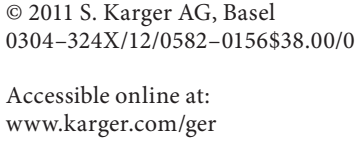


tive decline? One possibility is that age-related decline in brain regions that monitor negative, potentially threatening information reduces negative affect. This is the argument made by Cacioppo et al. [11] with their aging-brain model which proposes that age-related decline in the amygdala leads to the positivity effect. This argument is based on the observation that patients with amygdala lesions are worse at rating the arousal or intensity of negative stimuli, but not of positive stimuli $[12,13]$. Cacioppo et al. [11] propose that age-related decline in the amygdala selectively diminishes emotional arousal in response to negative stimuli (but not positive stimuli) and, as a result, older adults fail to get the memorial advantage of high arousal associated with negative stimuli and experience less negative affect.

A different possibility is that age-related diminishment of negative affect occurs because older adults are more focused on regulating emotion in their everyday lives. Previous research suggests that older adults are more likely than younger adults to prioritize emotion regulatory goals over other goals [14], and to regulate emotion when induced into a negative mood [15]. Effective emotion regulation requires self-directed attention and memory. For instance, attention should avoid negative information that could impair one's mood and memory processes should be directed to increase the prevalence of positive mood-enhancing thoughts. Being guided by emotion regulation goals rather than by currently salient stimuli requires the types of cognitive control processes implemented by the prefrontal cortex (PFC) [16].

Based on this line of reasoning, the cognitive control model $[3,4,7]$ argues that older adults' positivity effect is due to their greater focus on regulating emotions and requires cognitive control processes. This idea is consistent with behavioral evidence suggesting that the positivity effect emerges especially when older adults have enough cognitive resources, and when this effort is not readily available, they show no positivity effect $[6,17,18]$. Furthermore, the positivity effect is most robust for items low in arousal, as low arousing items are more likely to engage cognitive control processes whereas high arousing items require relatively automatic processes [9].

In this paper, we review recent functional magnetic resonance imaging (fMRI) studies of age differences in emotional processing and discuss how they relate to these two opposing theoretical accounts of older adults' positivity effect. The aging-brain and cognitive-control models make different predictions about how aging should affect brain activity during emotion processing. The aging-brain model argues that age-related functional de- cline in the amygdala causes the positivity effect, whereas the cognitive control model assumes that prefrontal regulation of emotional processing causes the positivity effect.

\section{Structural Preservation of the Amygdala in Aging}

Imaging studies indicate that there is less volumetric decline with age in the amygdala than in most other brain regions $[19,20]$ and postmortem measurements based on histological staining reveal no significant effect of age on amygdala volume [21]. Thus, contrary to the aging-brain model, older adults do not appear to suffer from focal damage in the amygdala and patients with amygdala damage are unlikely to be a useful neuropsychological model of the effects of aging.

Consistent with the structural preservation of the amygdala, emotional processing is well preserved in normal aging. Previous research suggests that the ability to detect emotionally arousing stimuli is relatively stable with age [22], and that the effects of emotional arousal on memory remain intact in normal aging [23]. Furthermore, younger and older adults produce similar skin conductance responses to emotionally arousing stimuli [23, 24].

\section{Functional Neuroimaging Comparisons of Younger and Older Adults' Amygdala Activity}

Despite structural preservation of the amygdala in normal aging, fMRI studies have revealed some age differences in amygdala activity. The difference seen most consistently across studies is an age-related decrease in activation in response to negative stimuli [25-28]. This decrease in amygdala activity in response to negative stimuli is predicted by both theoretical perspectives. The aging-brain model predicts that age-related amygdala decline reduces amygdala responsivity to emotionally arousing stimuli. In contrast, the cognitive-control model predicts that prefrontal emotion regulation processes diminish amygdala responses to negative but not positive stimuli. Therefore, age-related decreases in amygdala activity when viewing negative stimuli are not due to inherent amygdala impairments. Although both explanations are plausible, prior studies provide more evidence for the cognitive control model. Below, we first describe results consistent with the cognitive control model, followed by results contradicting the aging-brain model's assumptions. 
In line with the cognitive-control model, past studies revealed a link between diminished amygdala activity to negative stimuli and emotion regulation skills. In one study of participants between 30 and 54 years of age, but not younger adults, reduced amygdala activity to negative stimuli was associated with a trait tendency to use an effective emotion regulation strategy (i.e. reappraisal) [25]. That is, higher reappraisal tendency predicted lower amygdala activation while viewing negative stimuli than during neutral ones. Furthermore, in another study, older adults who showed a lower amygdala signal to negative stimuli showed more effective regulation of diurnal cortisol levels in the week following the scan [29]. Although these are correlational results, they suggest that older adults' reduced amygdala response to negative stimuli does not reflect impaired amygdala function, but instead emotion regulation efforts.

Furthermore, research on Alzheimer's disease (AD) provides a counterpoint to the aging-brain model's assumption that decreased amygdala activity is a sign of age-related decline in the amygdala. The amygdala is one of the brain regions typically most affected by $\mathrm{AD}$ [30]. A study comparing amygdala responses in younger, older, and $\mathrm{AD}$ patients while viewing familiar neutral and novel fearful human faces revealed that the $\mathrm{AD}$ group showed significantly greater amygdala responses to both types of faces relative to elderly controls [31]. Importantly, greater hyperactivity was associated with greater severity of irritability and agitation symptoms in AD. The results suggest that disease-related amygdala decline leads to hyperactive amygdala responses. Therefore, this reduced amygdala response to negative stimuli seen among healthy older adults is not a symptom of early AD.

In addition, contrary to the aging-brain model's assumption that the amygdala declines with age, there is evidence that the amygdala's function is preserved in healthy older adults [32]. First, in two studies that included both positive and negative pictures, age-related decreases in amygdala activity were seen for negative but not positive pictures $[25,26]$. Thus, even in older adults who showed reduced amygdala activity to negative stimuli, their amygdala can still be activated by a certain type of emotional stimuli. Second, the amygdala in older adults is sometimes activated even by negative stimuli. In one study [33], for example, both younger and older adults showed enhanced amygdala activity to negative photographs compared to neutral photographs. Importantly, the amygdala activation in older adults involved overlapping areas with younger adults, suggesting that older adults depend on the same amygdala regions to process negative stimuli as younger adults. Furthermore, research on emotional memory demonstrated that the amygdala plays an important role in enhancing memory for emotional stimuli both in younger and older adults [34-36]. Taken together, these findings suggest that the amygdala functions similarly in healthy older adults as it does in younger adults. Thus, it seems unlikely that the reduced amygdala activity to negative stimuli in older adults is caused by age-related impairment of the amygdala as the aging-brain model predicts.

\section{Age-Related Differences in PFC Activity during Emotion Processing}

While the cognitive-control and aging-brain models both predict reduced amygdala activity to negative stimuli in older adults, the two models make different predictions about PFC activity during emotion processing. In contrast to the aging-brain model, which makes no specific predictions about PFC responsivity to emotional stimuli, the cognitive control model argues that if older adults' positivity effects are the result of a greater focus on emotion regulation goals, older adults should recruit more PFC while encountering emotional stimuli than do younger adults because the PFC is involved in cognitive control of emotion $[16,29,37]$. Importantly, such age-related increases in PFC activity should exceed those seen in response to neutral stimuli. Increases in PFC activity are expected for downregulation of negative emotion (i.e. dampening of emotional responses or attentional avoidance of negative stimuli) and for upregulation of positive emotion (i.e. enhancing emotional responses to positive stimuli). To address these predictions, we review prior studies examining age differences in PFC activity in response to negative and positive stimuli (although there are fewer studies with positive stimuli; further investigation is needed).

\section{Greater PFC Activity to Negative Stimuli in Older Adults}

Consistent with the prediction made by the cognitive control model, a number of studies report that older adults recruited PFC more for negative than for neutral stimuli compared with younger adults (fig. 1; table 1). In one study [38], brain activity was measured by fMRI while younger and older adults made indoor-outdoor judgments (i.e. encoding session) and old-new recogni- 


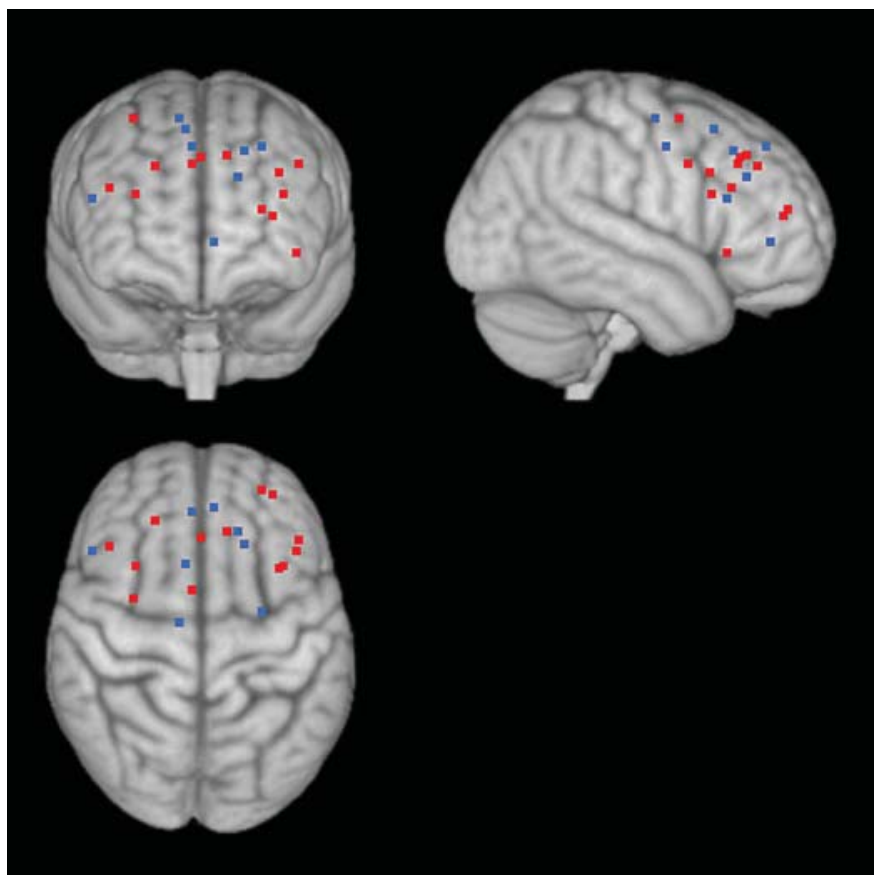

Fig. 1. Age differences in PFC involvement while processing negative stimuli. Negative stimuli induced greater PFC activity compared with neutral stimuli in older adults compared to younger adults (represented by black dots; online version: red dots). In some studies, where participants could anticipate negative stimuli, older adults showed less PFC activity than did younger adults (represented by white dots; online version: blue dots). See table 1 for a list of coordinates and studies used in the figure.

tion judgments about negative or neutral photographs (i.e. recognition session). The results indicated that older adults recruited dorsolateral PFC more strongly for negative photographs (than for neutral ones) compared with younger adults in the encoding session. Similar patterns were observed in the recognition session; older adults showed increased dorsolateral PFC activity to negative pictures together with reduced amygdala activity compared with younger adults. Other studies also reveal that older adults show increased PFC or anterior cingulate cortex (ACC) activity together with decreased amygdala activity while viewing negative stimuli $[27,28]$. In addition, relative to younger adults, older adults showed more negative functional connectivity between the right amygdala and ACC while rating emotional pictures [33]. Moreover, the negative correlation between these two regions was observed when older adults rated negative pictures as neutral, but not when they rated negative pictures as negative. These results are consistent with the cognitive control model, suggesting that PFC/ACC dampened activity in the amygdala while viewing negative stimuli, and that the enhanced PFC activity seen in older adults reflects their efforts to downregulate negative emotions.

Indeed, the PFC regions activated by older adults in these studies (and in others; see table 1) are similar to regions implicated in emotion regulation. For instance, Brodmann area (BA) 9 was also activated while people were told to downregulate their negative emotions to aversive stimuli $[37,39]$. Likewise, BA 6, 8, 10, 44, and 45 overlap with areas associated with downregulation of negative emotion [37]. While most emotion regulation findings are based on younger adults, a recent study found that cognitive reappraisal activated similar PFC regions to those mentioned above in both younger and older adults [40]. In addition, there is evidence of negative relationships between the amygdala and PFC during successful emotion regulation [41, 42], which is also consistent with the negative amygdala-PFC correlations seen in older adults when they encounter negative stimuli [33]. Taken together, these studies suggest that the enhanced PFC activity to negative stimuli coupled with decreased amygdala activity while encountering negative stimuli may reflect older adults' attempts to regulate their emotions.

\section{Greater PFC Activity to Positive versus Negative Stimuli in Older Adults}

In addition to increased PFC when processing negative stimuli, older adults sometimes recruit PFC more for positive than negative stimuli (relative to younger adults; see table 2 and fig. 2). Older adults' increased PFC activity to positive stimuli has been observed when a task requires more elaborative processing of emotional stimuli, rather than passive viewing (such as self-relevant processing [43], semantic judgments [44], or mental manipulation of the perceptual stimulus representation [45]). This may suggest that, when prompted to deeply process stimuli, older adults engage more with positive than negative stimuli. This idea is supported by two studies examining how the depth of encoding affects brain activity in younger and older adults.

In Ritchey et al. [44], younger and older adults viewed positive, negative, or neutral photographs, and either analyzed each picture for its semantic meanings (i.e. semantic elaboration condition), or focused on the colors and lines in the pictures (i.e. shallow condition). In older adults, positive stimuli induced greater activity in medial/superior PFC and inferior PFC under the semantic elaboration condition, but not under the shallow 
Table 1. Summary of neuroimaging studies showing age-related differences in prefrontal cortex activity to negative vs. neutral stimuli

\begin{tabular}{|c|c|c|c|c|c|c|c|c|}
\hline Study & Stimulus & Task & Contrast & Age effects & $\mathrm{BA}$ & $\mathrm{x}$ & $\mathrm{y}$ & $\mathrm{z}$ \\
\hline Roalf et al. [49] & $\begin{array}{l}\text { IAPS pictures (positive, } \\
\text { negative, or neutral) }\end{array}$ & passively viewing & [negative $>$ neutral] & $\mathrm{OA}>\mathrm{YA}$ & & -34 & 14 & 32 \\
\hline Williams et al. [48] & $\begin{array}{l}\text { faces } \\
\text { (fear, happy, or neutral) }\end{array}$ & passively viewing & [negative > neutral] & $\begin{array}{l}\mathrm{OA}>\mathrm{YA} \\
\mathrm{OA}>\mathrm{YA}\end{array}$ & $\begin{array}{l}8 \\
8\end{array}$ & $\begin{array}{r}-18 \\
6\end{array}$ & $\begin{array}{l}25 \\
40\end{array}$ & $\begin{array}{l}42 \\
44\end{array}$ \\
\hline \multirow[t]{3}{*}{ Murty et al. [38] } & $\begin{array}{l}\text { IAPS pictures (negative or } \\
\text { neutral) }\end{array}$ & indoor-outdoor judgment & [negative $>$ neutral] & $\mathrm{OA}>\mathrm{YA}$ & 10 & -26 & 50 & 15 \\
\hline & $\begin{array}{l}\text { IAPS pictures (negative or } \\
\text { neutral) }\end{array}$ & recognition task & [negative > neutral] & $\mathrm{OA}>\mathrm{YA}$ & 46 & 44 & 24 & 25 \\
\hline & $\begin{array}{l}\text { IAPS pictures (negative or } \\
\text { neutral) }\end{array}$ & recognition task & [negative > neutral] & $\mathrm{OA}>\mathrm{YA}$ & 24 & 6 & 4 & 36 \\
\hline Tessitore et al. [27] & $\begin{array}{l}\text { faces (fear or angry) or } \\
\text { geometric shapes }\end{array}$ & $\begin{array}{l}\text { facial expression matching } \\
\text { task or sensorimotor task }\end{array}$ & [negative-neutral] & $\begin{array}{l}\mathrm{OA}>\mathrm{YA} \\
\mathrm{OA}>\mathrm{YA} \\
\mathrm{OA}>\mathrm{YA}\end{array}$ & $\begin{array}{c}9 \\
44 / 45 \\
8\end{array}$ & $\begin{array}{r}-36 \\
32 \\
-10\end{array}$ & $\begin{array}{l}15 \\
15 \\
31\end{array}$ & $\begin{array}{l}22 \\
22 \\
40\end{array}$ \\
\hline St. Jacques et al. [34] & $\begin{array}{l}\text { IAPS pictures (negative or } \\
\text { neutral) }\end{array}$ & valence rating & $\begin{array}{l}\text { [negative R-negative F] > } \\
{[\text { neutral R-neutral F] }}\end{array}$ & $\mathrm{OA}>\mathrm{YA}$ & 9 & -43 & 27 & 36 \\
\hline St. Jacques et al. [33] & $\begin{array}{l}\text { IAPS pictures } \\
\text { (negative or neutral) }\end{array}$ & valence rating & [negative $>$ neutral] & $\begin{array}{l}\mathrm{OA}>\mathrm{YA} \\
\mathrm{OA}>\mathrm{YA}\end{array}$ & $\begin{array}{l}6 \\
9\end{array}$ & $\begin{array}{r}33 \\
2\end{array}$ & $\begin{array}{r}0 \\
28\end{array}$ & $\begin{array}{l}57 \\
39\end{array}$ \\
\hline Fischer et al. [35] & faces (fearful or neutral) & fear or neutral judgment & $\begin{array}{l}\text { [negative R-negative F] > } \\
\text { [neutral R-neutral F] }\end{array}$ & $\mathrm{OA}>\mathrm{YA}$ & 9 & 23 & 36 & 35 \\
\hline \multirow[t]{2}{*}{ Erk et al. [25] } & $\begin{array}{l}\text { cues predicting IAPS } \\
\text { pictures (negative, positive, } \\
\text { or neutral) }\end{array}$ & $\begin{array}{l}\text { anticipating a picture } \\
\text { corresponding to the } \\
\text { valence of the cue }\end{array}$ & [negative $>$ neutral] & $\mathrm{YA}>\mathrm{OA}$ & 32 & -4 & 42 & 0 \\
\hline & $\begin{array}{l}\text { IAPS pictures (positive, } \\
\text { negative or neutral) }\end{array}$ & passively viewing & [negative $>$ neutral] & $\mathrm{YA}>\mathrm{OA}$ & 46 & 52 & 22 & 20 \\
\hline Williams et al. [48] & $\begin{array}{l}\text { faces } \\
\text { (fear, happy, or neutral) }\end{array}$ & passively viewing & [negative $>$ neutral] & $\begin{array}{l}\mathrm{YA}>\mathrm{OA} \\
\mathrm{YA}>\mathrm{OA}\end{array}$ & $\begin{array}{l}8 \\
8\end{array}$ & $\begin{array}{r}-18 \\
6\end{array}$ & $\begin{array}{l}25 \\
40\end{array}$ & $\begin{array}{l}42 \\
44\end{array}$ \\
\hline St. Jacques et al. [34] & $\begin{array}{l}\text { IAPS pictures } \\
\text { (negative or neutral) }\end{array}$ & valence rating & $\begin{array}{l}{[\text { negative R-negative } \mathrm{F}]>} \\
{[\text { neutral R-neutral F] }}\end{array}$ & $\begin{array}{l}\mathrm{YA}>\mathrm{OA} \\
\mathrm{YA}>\mathrm{OA} \\
\mathrm{YA}>\mathrm{OA} \\
\mathrm{YA}>\mathrm{OA}\end{array}$ & $\begin{array}{l}6 \\
9 \\
6 \\
6\end{array}$ & $\begin{array}{r}-26 \\
-15 \\
9 \\
12\end{array}$ & $\begin{array}{r}-6 \\
31 \\
16 \\
-11\end{array}$ & $\begin{array}{l}44 \\
30 \\
52 \\
57\end{array}$ \\
\hline
\end{tabular}

$\mathrm{R}=$ Remembered $\mathrm{F}=$ forgotten $\mathrm{YA}=$ younger adults; $\mathrm{OA}=$ older adults; $\mathrm{BA}=$ Brodmann area. Coordinates are in MNI space and plotted in figure 1.

condition. In contrast, in younger adults, these PFC clusters showed similar levels of activity to positive stimuli regardless of the condition. Similar results were observed in another study [43]; compared with younger adults, older adults recruited medial and middle PFC more for positive items relative to negative items when they made self-referential judgments about those stimuli (relative to other-referential judgments). Both semantic elaboration and self-referential processing are known to induce deep processing, requiring cognitive effort [46]. Thus, it appears that older adults recruit PFC for positive stimuli especially when they process those stimuli deeply.
According to the cognitive control model, older adults' greater PFC activity for positive stimuli described above is a result of their effort to upregulate emotion to experience more positive affect. If this is the case, older adults' brain regions activated while processing positive stimuli should also activate when people upregulate or try to amplify their positive emotions. Although most emotion regulation studies have focused on downregulation of negative affect, one study [47] used positive and negative stimuli in order to identify regions critical for upregulation of positive emotions. The identified regions included the dorsomedial PFC (BA 6), the left PFC (BA 8), the medial PFC (BA 10), the medial orbitofrontal cortex (BA 11), and left orbitofrontal cortex (BA 47). Importantly, these 


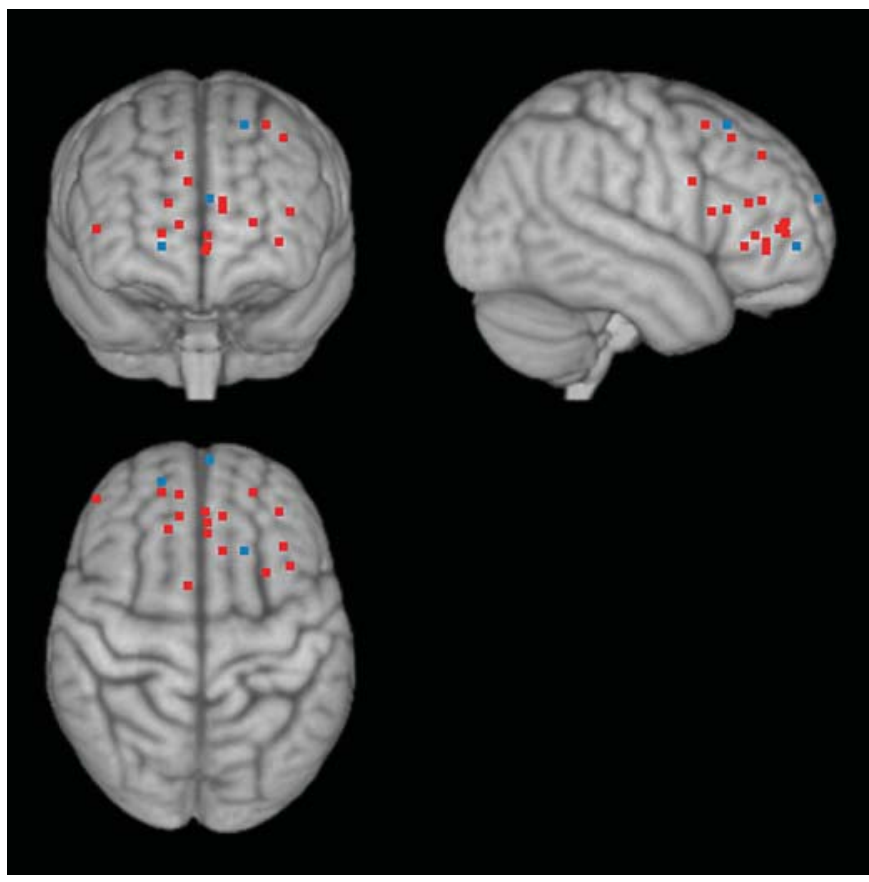

Fig. 2. Age differences in PFC involvement while processing positive stimuli. Although some studies showed greater PFC activity to positive stimuli than to neutral stimuli in younger adults than in older adults (shown by white dots; online version: blue dots), in studies with tasks requiring deep processing of stimuli, older adults recruited PFC more for positive stimuli than for negative stimuli (relative to younger adults), which is shown by black dots (online version: red dots). See table 2 for a list of coordinates and studies used in the figure.

regions were similar to those activated more for positive than negative stimuli while older adults were deeply engaged with these stimuli (BA 8, 10, 11, and 47 shown in table 2). This provides further support for the cognitive control model, suggesting that older adults tend to recruit PFC when encountering positive stimuli in order to feel more positive.

\section{Questions for Future Research}

While many studies have reported enhanced PFC activity to emotional stimuli in older in comparison to younger adults (as reviewed above), a few studies have reported decreased PFC activity to positive stimuli [25, 48 ] and negative stimuli in older adults compared to younger adults $[25,49]$. Some of these age-related reductions in PFC activity during emotion processing may be related to the stimuli presentation sequences used. For instance, in one such study [25], participants were given symbolic cues that informed them about the valence of the subsequent picture. Being able to anticipate negative emotional stimuli may have allowed older adults to engage in antecedent-focused regulation (strategies to regulate emotion before the emotional response has already been fully activated [50]) rather than response-focused regulation that requires more cognitive control. In another study [49], participants viewed blocks of 40 pictures of the same valence for $80 \mathrm{~s}$. Overall, older adults had reduced amygdala activity compared with younger adults, especially while viewing the negative pictures. Older adults also showed more PFC activity than younger adults during the first 20 negative pictures, but this greater prefrontal activity habituated by the second half of the blocks. Younger adults did not show this pattern of habituation for any emotional valence and older adults only showed it for the negative pictures. It is possible that, during the 80 -second long blocks of negative pictures, older participants initially had emotional responses to each picture and then attempted to downregulate these emotional responses. As the series of negative pictures continued, however, they may have switched to less taxing antecedent-focused strategies in which they attempted to avoid having a response to the pictures in the first place. Further research is needed to investigate the role of anticipation of negative affect and how it might affect older adults' $\mathrm{PFC}$ engagement while processing negative stimuli.

\section{Summary and Future Directions}

This paper compares two theoretical accounts for older adults' positivity effect. The aging-brain model proposes that age-related decline in amygdala activation in response to negative stimuli causes an age-related positivity bias in cognition. In contrast, the cognitive control model argues that older adults' motivational changes direct cognitive control processes to regulate emotion, leading to a positivity effect. Arguing against the agingbrain model, previous neuroimaging evidence suggests that the amygdala remains structurally intact and functionally responsive to various types of stimuli including negatively valenced items. Furthermore, although participants were not instructed to regulate negative or positive emotions explicitly in most studies cited in this paper, older adults showed enhanced PFC activity during emotion processing tasks (relative to neutral conditions) compared with younger adults. These observations are 
Table 2. Summary of neuroimaging studies showing age-related differences in prefrontal cortex activity to positive vs. negative or neutral stimuli

\begin{tabular}{|c|c|c|c|c|c|c|c|c|}
\hline Study & Stimulus & Task & Contrast & Age effects & BA & $\mathrm{x}$ & $\mathrm{y}$ & $\mathrm{z}$ \\
\hline Addis et al. [45] & $\begin{array}{l}\text { photo objects (positive, } \\
\text { negative, or neutral) }\end{array}$ & size judgments & [positive $>$ negative] & $\begin{array}{l}\mathrm{OA}>\mathrm{YA} \\
\mathrm{OA}>\mathrm{YA}\end{array}$ & $\begin{array}{l}10 / 32 \\
10 / 11 / 47\end{array}$ & $\begin{array}{r}-1 \\
-34\end{array}$ & $\begin{array}{l}35 \\
40\end{array}$ & $\begin{array}{l}3 \\
0\end{array}$ \\
\hline $\begin{array}{l}\text { Kensinger and } \\
\text { Schacter [36] }\end{array}$ & $\begin{array}{l}\text { photo objects (positive, } \\
\text { negative, or neutral) }\end{array}$ & $\begin{array}{l}\text { size judgments during } \\
\text { encoding and } \\
\text { recognition test }\end{array}$ & $\begin{array}{l}\text { [positive } \mathrm{R}>\text { positive } \mathrm{F} \text { - } \\
{[\text { negative or neutral } \mathrm{R}>} \\
\text { negative or neutral } \mathrm{F} \text { ] }\end{array}$ & $\begin{array}{l}\mathrm{OA}>\mathrm{YA} \\
\mathrm{OA}>\mathrm{YA} \\
\mathrm{OA}>\mathrm{YA}\end{array}$ & $\begin{array}{l}10 \\
24 \\
33\end{array}$ & $\begin{array}{r}-1 \\
-8 \\
8\end{array}$ & $\begin{array}{r}30 \\
22 \\
6\end{array}$ & $\begin{array}{l}-2 \\
15 \\
28\end{array}$ \\
\hline $\begin{array}{l}\text { Leclerc and } \\
\text { Kensinger [22] }\end{array}$ & $\begin{array}{l}\text { photo objects (positive, } \\
\text { negative, or neutral) }\end{array}$ & size judgments & [positive $>$ negative] & $\begin{array}{l}\mathrm{OA}>\mathrm{YA} \\
\mathrm{OA}>\mathrm{YA} \\
\mathrm{OA}>\mathrm{YA}\end{array}$ & $\begin{array}{r}8 \\
32 \\
32\end{array}$ & $\begin{array}{r}-36 \\
0 \\
12\end{array}$ & $\begin{array}{l}24 \\
40 \\
48\end{array}$ & $\begin{array}{r}48 \\
-4 \\
8\end{array}$ \\
\hline Ritchey et al. [44] & $\begin{array}{l}\text { IAPS pictures } \\
\text { (positive, negative, } \\
\text { or neutral) }\end{array}$ & $\begin{array}{l}\text { semantic elaboration } \\
\text { or color processing }\end{array}$ & $\begin{array}{l}\text { age } \mathrm{X} \text { task X valence masked } \\
\text { with [positive }>\text { negative in } \mathrm{OA} \text { ] } \\
\mathrm{X}[\text { deep }>\text { shallow in } \mathrm{OA}]\end{array}$ & $\begin{array}{l}\mathrm{OA}>\mathrm{YA} \\
\mathrm{OA}>\mathrm{YA} \\
\mathrm{OA}>\mathrm{YA} \\
\mathrm{OA}>\mathrm{YA} \\
\mathrm{OA}>\mathrm{YA}\end{array}$ & $\begin{array}{l}32 \\
10 \\
10 \\
10 \\
45\end{array}$ & $\begin{array}{r}17 \\
-8 \\
-22 \\
20 \\
-39\end{array}$ & $\begin{array}{l}32 \\
38 \\
49 \\
49 \\
15\end{array}$ & $\begin{array}{r}18 \\
19 \\
9 \\
4 \\
14\end{array}$ \\
\hline Gutchess et al. [43] & $\begin{array}{l}\text { positive and negative } \\
\text { adjectives }\end{array}$ & $\begin{array}{l}\text { self, other (Einstein) } \\
\text { or case judgments }\end{array}$ & $\begin{array}{l}\text { [self positive-other positive] }> \\
\text { [self negative-other negative] }\end{array}$ & $\begin{array}{l}\mathrm{OA}>\mathrm{YA} \\
\mathrm{OA}>\mathrm{YA} \\
\mathrm{OA}>\mathrm{YA}\end{array}$ & $\begin{array}{r}8 \\
45 \\
32\end{array}$ & $\begin{array}{r}-28 \\
50 \\
12\end{array}$ & $\begin{array}{l}12 \\
46 \\
38\end{array}$ & $\begin{array}{r}54 \\
6 \\
40\end{array}$ \\
\hline Erk et al. [25] & $\begin{array}{l}\text { IAPS pictures (positive, } \\
\text { negative, or neutral) }\end{array}$ & passively viewing & [positive $>$ neutral] & $\mathrm{YA}>\mathrm{OA}$ & 9 & -2 & 64 & 20 \\
\hline Williams et al. [48] & faces (fear, happy, neutral) & passively viewing & [positive $>$ neutral] & $\begin{array}{l}\mathrm{YA}>\mathrm{OA} \\
\mathrm{YA}>\mathrm{OA}\end{array}$ & $\begin{array}{r}6 \\
10\end{array}$ & $\begin{array}{r}-18 \\
20\end{array}$ & $\begin{array}{l}22 \\
54\end{array}$ & $\begin{array}{l}54 \\
-2\end{array}$ \\
\hline
\end{tabular}

$\mathrm{R}=$ Remembered $; \mathrm{F}$ = forgotten $\mathrm{YA}=$ younger adults; $\mathrm{OA}=$ older adults; $\mathrm{BA}=\mathrm{Brodmann}$ area. Coordinates are in MNI space and plotted in figure 2 .

consistent with the possibility that emotion regulation goals are more chronically active for older adults than for younger adults $[4,7]$. This idea is further supported by the overlap in brain regions activated during emotion processing (with no instructions to regulate emotions induced by emotional stimuli) and during emotion regulation (with specific instructions to regulate emotion).

Future research should investigate age differences in brain activity during spontaneous versus strategic emotion regulation (especially upregulation of positive emotion, which has not been well investigated). This would elucidate how much of older adults' emotion regulation mechanism is chronically activated and how much of it is intentional, and how these underlying mechanisms affect their mood and cognition in general.

\section{Acknowledgements}

This work was supported by grants from the National Institute on Aging (R01AG025340, R01AG038043, K02AG032309 and 5T32AG000037). We would also like to acknowledge Lin Nga for assisting with the figures.

\section{References}

Salthouse TA: Selective review of cognitive aging. J Int Neuropsychol Soc 2010;16:754760.

2 Charles ST, Piazza JR: Age differences in affective well-being: context matters. Soc Personal Psychol Compass 2009;3:1-14.

3 Kryla-Lighthall N, Mather M: The role of cognitive control in older adults' emotional well-being; in Berngtson V, Gans D, Putney N, Silverstein M (eds): Handbook of Theories of Aging, ed 2. New York, Springer Publishing, 2009, pp 323-344.
4 Mather M, Carstensen LL: Aging and motivated cognition: the positivity effect in attention and memory. Trends Cogn Sci 2005;9: 496-502.

5 Mather M, Carstensen LL: Aging and attentional biases for emotional faces. Psychol Sci 2003;14:409.

6 Knight M, Seymour TL, Gaunt JT, Baker C, Nesmith K, Mather M: Aging and goal-directed emotional attention: distraction reverses emotional biases. Emotion 2007;7: 705-714.
7 Mather M, Knight M: Goal-directed memory: the role of cognitive control in older adults' emotional memory. Psychol Aging 2005;20:554-570.

8 Charles ST, Mather M, Carstensen LL: Aging and emotional memory: the forgettable nature of negative images for older adults. J Exp Psychol Gen 2003;132:310-324.

-9 Kensinger EA: Age differences in memory for arousing and nonarousing emotional words. J Gerontol B Psychol Sci Soc Sci 2008; 63:P13-P18. 
10 Murphy NA, Isaacowitz DM: Preferences for emotional information in older and younger adults: a meta-analysis of memory and attention tasks. Psychol Aging 2008;23:263-286.

11 Cacioppo JT, Berntson GG, Bechara A, Tranel D, Hawkley LC: Could an aging brain contribute to subjective well-being? The value added by a social neuroscience perspective; in Todorov A, Fiske S, Prentice D (eds): Social Neuroscience: Toward Understanding the Underpinnings of the Social Mind. New York, Oxford University Press, 2011, p 249.

-12 Berntson GG, Bechara A, Damasio H, Tranel D, Cacioppo JT: Amygdala contribution to selective dimensions of emotion. Soc Cogn Affect Neurosci 2007;2:123-129.

-13 Adolphs R, Tranel D: Impaired judgments of sadness but not happiness following bilateral amygdala damage. J Cogn Neurosci 2004;16: 453-462.

14 Carstensen LL, Isaacowitz DM, Charles ST: Taking time seriously. A theory of socioemotional selectivity. Am Psychol 1999;54:165181.

-15 Isaacowitz DM, Toner K, Goren D, Wilson HR: Looking while unhappy: mood-congruent gaze in young adults, positive gaze in older adults. Psychol Sci 2008;19:848-853.

-16 Ochsner KN, Gross JJ: The cognitive control of emotion. Trends Cogn Sci 2005;9:242249.

17 Isaacowitz DM, Toner K, Neupert SD: Use of gaze for real-time mood regulation: effects of age and attentional functioning. Psychol Aging 2009;24:989-994.

18 Petrican R, Moscovitch M, Schimmack U: Cognitive resources, valence, and memory retrieval of emotional events in older adults. Psychol Aging 2008;23:585-594.

19 Mather M: Aging and emotional memory; in Reisberg D, Hertel P (eds): Memory and Emotion. London, Oxford University Press, 2004, pp 272-307.

-20 Allen JS, Bruss J, Brown CK, Damasio H: Normal neuroanatomical variation due to age: the major lobes and a parcellation of the temporal region. Neurobiol Aging 2005;26: 1245-1260.

-21 BrabecJ, Rulseh A, Hoyt B, Vizek M, Horinek D, Hort J, Petrovicky P: Volumetry of the human amygdala - an anatomical study. Psychiatry Res 2010;182:67-72.

22 Leclerc CM, Kensinger EA: Effects of age on detection of emotional information. Psychol Aging 2008;23:209-215.

-23 Denburg NL, Buchanan D, Tranel D, Adolphs R: Evidence for preserved emotional memory in normal elderly persons. Emotion 2003:3:239-253.

-24 Neiss MB, Leigland LA, Carlson NE, Janowsky JS: Age differences in perception and awareness of emotion. Neurobiol Aging 2009;30:1305-1313.
25 Erk S, Walter H, Abler B: Age-related physiological responses to emotion anticipation and exposure. Neuroreport 2008;19:447452.

26 Mather M, Canli T, English T, Whitfield SL, Wais PE, Ochsner KN, John DEG, Carstensen LL: Amygdala responses to emotionally valenced stimuli in older and younger adults. Psychol Sci 2004;15:259-263.

27 Tessitore A, Hariri AR, Fera F, Smith WG, Das S, Weinberger DR, Mattay VS: Functional changes in the activity of brain regions underlying emotion processing in the elderly Psychiatry Res 2005;139:9-18.

28 Fischer H, Sandblom J, Gavazzeni J, Fransson P, Wright CI, Backman L: Age-differential patterns of brain activation during perception of angry faces. Neurosci Lett 2005. 386:99-104.

29 Urry HL, van Reekum CM, Johnstone T, Kalin NH, Thurow ME, Schaefer HS, Jackson CA, Frye CJ, Greischar LL, Alexander AL, Davidson RJ: Amygdala and ventromedial prefrontal cortex are inversely coupled during regulation of negative affect and predict the diurnal pattern of cortisol secretion among older adults. J Neurosci 2006;26: 4415-4425.

30 Liu Y, Paajanen T, Zhang Y, Westman E, Wahlund LO, Simmons A, Tunnard C, Sobow T, Mecocci P, Tsolaki M, Vellas B, Muehlboeck S, Evans A, Spenger C, Lovestone S, Soininen H: Analysis of regional MRI volumes and thicknesses as predictors of conversion from mild cognitive impairment to Alzheimer's disease. Neurobiol Aging 2010;31:1375-1385.

31 Wright CI, Dickerson BC, Feczko E, Negeira A, Williams D: A functional magnetic resonance imaging study of amygdala responses to human faces in aging and mild Alzheimer's disease. Biol Psychiatry 2007;62:13881395.

32 Wright CI, Negreira A, Gold AL, Britton JC Williams D, Feldman Barrett L: Neural correlates of novelty and face-age effects in young and elderly adults. Neuroimage 2008; 42:956-968

-33 St. Jacques PL, Dolcos F, Cabeza R: Effects of aging on functional connectivity of the amygdala during negative evaluation: a network analysis of fMRI data. Neurobiology Aging 2010;31:315-327.

34 St. Jacques PL, Dolcos F, Cabeza R: Effects of aging on functional connectivity of the amygdala for subsequent memory of negative pictures. Psychol Sci 2009;20:74-84.

35 Fischer H, Nyberg L, Backman L: Age-related differences in brain regions supporting successful encoding of emotional faces. Cortex 2010;46:490-497.

36 Kensinger EA, Schacter DL: Neural processes supporting young and older adults' emotional memories. J Cogn Neurosci 2008;20: 1161-1173.
37 Ochsner KN, Ray RD, Cooper JC, Robertson ER, Chopra S, Gabrieli JDE, Gross JJ: For better or for worse: neural systems supporting the cognitive down- and up-regulation of negative emotion. Neuroimage 2004;23: 483-499.

38 Murty VP, Sambataro F, Das S, Tan H-Y, Callicott JH, Goldberg TE, Meyer-Lindenberg A, Weinberger DR, Mattay VS: Age-related alterations in simple declarative memory and the effect of negative stimulus valence. J Cogn Neurosci 2009;21:1920-1933.

-39 van Reekum CM, Johnstone T, Urry HL, Thurow ME, Schaefer HS, Alexander AL, Davidson RJ: Gaze fixations predict brain activation during the voluntary regulation of picture-induced negative affect. Neuroimage 2007;36:1041-1055.

$\checkmark 40$ Winecoff A, Labar KS, Madden DJ, Cabeza $R$, Huettel SA: Cognitive and neural contributors to emotion regulation in aging. Soc Cogn Affect Neurosci 2011;6:165-176.

41 Urry HL, van Reekum CM, Johnstone T, Davidson RJ: Individual differences in some (but not all) medial prefrontal regions reflect cognitive demand while regulating unpleasant emotion. Neuroimage 2009;47:852-863.

42 Wager TD, Davidson ML, Hughes BL, Lindquist MA, Ochsner KN: Prefrontal-subcortical pathways mediating successful emotion regulation. Neuron 2008;59:1037-1050.

43 Gutchess AH, Kensinger EA, Schacter DL: Aging, self-referencing, and medial prefrontal cortex. Soc Neurosci 2007;2:117.

44 Ritchey M, Bessette-Symons B, Hayes SM, Cabeza R: Emotion processing in the aging brain is modulated by semantic elaboration. Neuropsychologia 2011;49:640-650.

45 Addis DR, Leclerc CM, Muscatell K, Kensinger EA: There are age-related changes in neural connectivity during the encoding of positive, but not negative, information. Cortex 2009;46:425-433

46 Glisky EL, Marquine MJ: Semantic and selfreferential processing of positive and negative trait adjectives in older adults. Memory 2009; 17:144-157.

47 Kim SH, Hamann S: Neural correlates of positive and negative emotion regulation. J Cogn Neurosci 2007;19:776-798.

48 Williams LM, Brown KJ, Palmer D, Liddell BJ, Kemp AH, Olivieri G, Peduto A, Gordon E: The mellow years? Neural basis of improving emotional stability over age. J Neurosci 2006;26:6422-6430

49 Roalf DR, Pruis TA, Stevens AA, Janowsky JS: More is less: emotion induced prefrontal cortex activity habituates in aging. Neurobiol Aging 2009, E-pub ahead of print.

50 Gross JJ: Emotion regulation in adulthood: timing is everything. Curr Dir Psychol Sci 2001;10:214-219. 